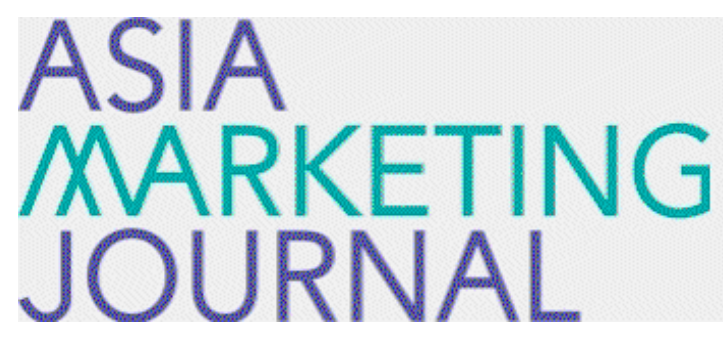

ASIA MARKETING JOURNAL

Volume 19 | Issue 2

Article 4

7-30-2017

\title{
The Reversed Effects of Advertising of Socially Controversial Products on Endorsers
}

Seoyoung Hwang

Junghoon Moon

Hyun Joo Lim

Jeong

Follow this and additional works at: https://amj.kma.re.kr/journal

Part of the Marketing Commons

\section{Recommended Citation}

Hwang, Seoyoung; Moon, Junghoon; Lim, Hyun Joo; and Jeong (2017) "The Reversed Effects of Advertising of Socially Controversial Products on Endorsers," Asia Marketing Journal: Vol. 19 : Iss. 2 , Article 4.

Available at: https://doi.org/10.15830/amj.2017.19.2.63

This Article is brought to you for free and open access by Asia Marketing Journal. It has been accepted for inclusion in Asia Marketing Journal by an authorized editor of Asia Marketing Journal. 


\title{
The Reversed Effects of Advertising of Socially Controversial Products on Endorsers*
}

\author{
Seoyoung Hwang** \\ Junghoon Moon** \\ Hyun Joo Lim*** \\ Jaeseok Jeong****
}

\begin{abstract}
This study investigated the impact of advertising of socially controversial products on its endorsers and products, and the role of media in moderating the results. Using the source credibility model with 174 survey samples, advertising of controversial products as a form of product placement (PPL) was found to have negative impact on consumers' attitude toward the endorsers. The results also confirmed that the moderating effect of media credibility on consumers when developing perceptions toward the endorsers. The results suggest marketing managers to use endorsers with careful consideration in designing advertising messages for socially controversial products, especially when delivered as a product placement on television.
\end{abstract}

Key words: Socially Controversial Food Advertisement, Product Placement Advertisement, Balance-Logic Theory, Source Credibility Model

\section{Introduction}

Along with advancement of technology and active interaction between countries especially in terms of communication and trade, consumers of today's world are exposed to unprecedented variety of goods and services. Consequently, the growing range of purchase options available for consumers have resulted in increased

\footnotetext{
* This research was supported by the MSIT(Ministry of Science and ICT), Korea, under the ITRC(Information Technology Research Center) support program(IITP-2017-2013-0-00877) supervised by the IITP(Institute for Information \& communications Technology Promotion).

** Food Business Lab., Program in Regional Information, College of Agriculture and Life Science, Seoul National University

*** Graduate School of Pan-Pacific International Studies, Kyung Hee University

**** Professor of Graduate School of Pan-Pacific International Studies, Kyung Hee University(profjeong@khu.ac.kr), Corresponding Author
} 
competition among firms, leading companies to employ diverse strategies to effectively advertise their products in the market. As a tactic to reach consumers with greater appeal, a large number of companies employ celebrities to endorse their products hoping the figure's credibility to enhance the brand's image. But how far would this belief be supported?

Many marketers fail to realize that not all advertisements are favored by consumers. While some messages manage to generate positive responses among the viewers, others get ignored, or even arouse the feeling of unpleasantness for the audiences. Usually the latter reaction seems to be more common when the advertisement is promoting socially sensitive products and services like gender related goods; contraceptives; cigarettes; alcoholic beverages; undergarments; lottery and more. And such advertisings that can potentially stimulate negative emotions like anger, aversion, and outrage among their viewers was termed "socially controversial advertisements" by Wilson and West (1981).

The current advertising literatures provide cases on endorsement effect on the image of advertised product; however, regarding socially controversial products, studies examining the product's influence on the endorser's image do not seem to be available. On that account, this research aims to examine the impact of advertising socially controversial products on the endorser, as well as its medium of delivery and the product itself.

To investigate the impact of advertising socially controversial products, the experiment was performed by using the advertisement stimuli employing genetically modified (GM) food product because of its socially controversial reputation to consumers.

\section{Conceptual Background}

\subsection{Advertising of Controversial Products}

Over the last decades, many studies have discussed about how controversial products should be defined and how their unique traits are related to advertising. The stream of works have developed to form two broad groups of interest where the former is represented by the works of Waller and Erdogan (2004), Waller (2006), and Waller, Fam, and Erdogan (2005) focused on socially controversial objects as the subject of advertising (e.g. cigarettes, alcoholic beverages, undergarments, lottery and more) (see Figure 1) and categorization of the products; whereas the latter highlighting the controversial expression or the concept used to advertise a genuine good (e.g., Benetton's UNHATE campaigns) (refer to Figure 2).

The reason why scholars continue to study about different aspects of controversial advertising, whether the focus is on the product itself or 
the message, is because the short TV commercial, such as a 15 to 30 -second commercial, is influential enough to manipulate a consumer's perception. This is evident considering the wide range of researches from Lavidge and Steiner (1961), McDonald (1992), Starch (1925) to Strong (1925) examining the effect of advertising on brand image, along with various models like the Starch test, the Attention-Interest-DesireAction (AIDA), and the hierarchy of effects models.

〈Figure 1〉 Euro Millions Lottery Advertisement

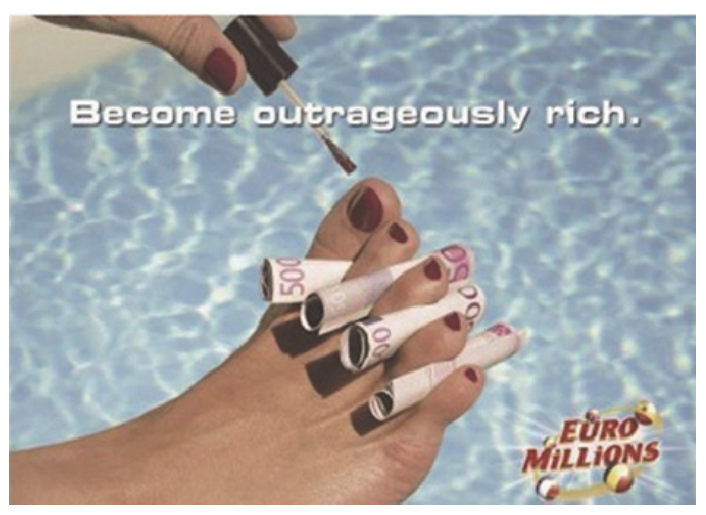

〈Figure 2〉 Benetton's 2011 UNHATE Advertisement

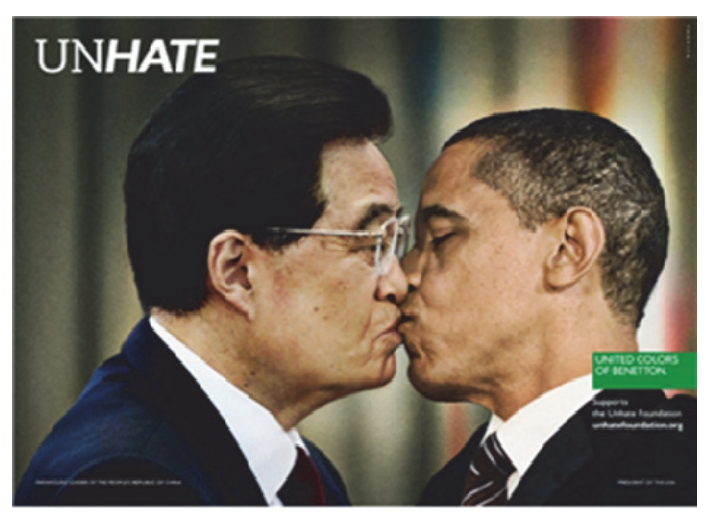

In order to understand how different advertising messages alter consumers' perception toward products, Rossiter and Percy's (1987) study needs to be consulted. Rossiter and Percy's model presents the process it takes for consumers to show a certain behavior as a response to being exposed to an advertisement. This model later served as the foundation for many researches dealing with controversial advertising and consumer attitude, like Fam and Waller (2003, 2008), and Waller's (1999) work on how such advertisements are conceived by consumers of diverse cultural backgrounds. A more comprehensive model of Rossiter and Percy's was introduced in 2006 by Waller, modified to encounter consumer behavior toward controversial advertisings.

\subsection{Controversial Product Advertising and Consumer Attitudes}

It has been suggested that the consumers generally undergo a certain process to generate some action as a result of encountering a new piece of information (advertisement). According to Rossiter and Percy (1987), by going through the stages of exposure to processing and communication effects leading to action, consumers can interpret and form an opinion about different messages advertised and make physical decisions accordingly (see Figure 3).

Starting with the stage of "exposure" a consumer encounters an advertising for the 
first time, and proceeds to "processing" of information for interpretation of messages, based on which a consumer engages in "communication effects" by interacting with other consumers to further develop attitudes and perceptions about the product. This finally leads to "action", like making purchase of the advertised product, spreading word of mouth, ignoring, or filling complaints to regulatory agencies. Here, usually positive communication from the former stage leads to positive actions and perceptions, and vice versa. This model, however, has its limits when considering controversial product advertising and consumer attitudes.

The Advertising Communication Models of Rossiter and Percy (1987) has been elaborated by Waller (2006) to differentiate the process leading to action between controversial goods and genuine products. The expanded model consists of five stages, through which consumers process socially controversial advertisings internally (refer to Figure 4). While Waller's model shares the four stages of "exposure" to "action" introduced by the Advertising Communication Models, they tend to show different implications for controversial advertisings.

For instance, Wilson and West (1981) observed that in the stage of "processing" controversial advertising, most consumers are inclined to show negative emotional responses like "distaste", "disgust", "offended", and "outrage", while only a small number shows positive attitudes like "attention”, “association”, "humor”, and "liking". Since the remaining stages are the extension of the "processing", it is more likely for controversial advertising to generate unfavorable perceptions toward the products. In fact, in the "communication effect" process, consumers have greater potential to engage in adverse communications based on the negative emotions formed in the "processing" stage. The similar may go for the "action" stage, where it is also likely for the message to be ignored by consumers, negative word of mouth is spread, or even disapproved by regulatory offices.

In Waller's (2006) model, another important attribute that significantly affects a consumer's communication with advertising is the "type of product" being advertised. In fact, a number of researchers have argued that socially controversial products, when advertised, generate negative responses among consumers (Phau and Prendergast 2001, Schuster and Powell 1987, Waller 2004, Wilson and West 1995). Thereby, one should not expect the same behavior from consumers for product advertisings concerning cigarettes, alcohol, underwear, and even political campaigns to that of genuine products (Barnes and Dotson 1990, Fahy, Smart, Pride and Ferrell 1995, Fam, Waller and Erdogan 2004, Rehman and Brooks 1987, Waller 1999, Waller, Fam and Erdogan 2005, Wilson and West 1981).

It can be inferred from both works proposed by Rossiter and Percy (1987) and Waller (2006) that the behaviors consumers show following 
〈Figure 3〉 Rossiter \& Percy's Advertising Communication Models (1987)

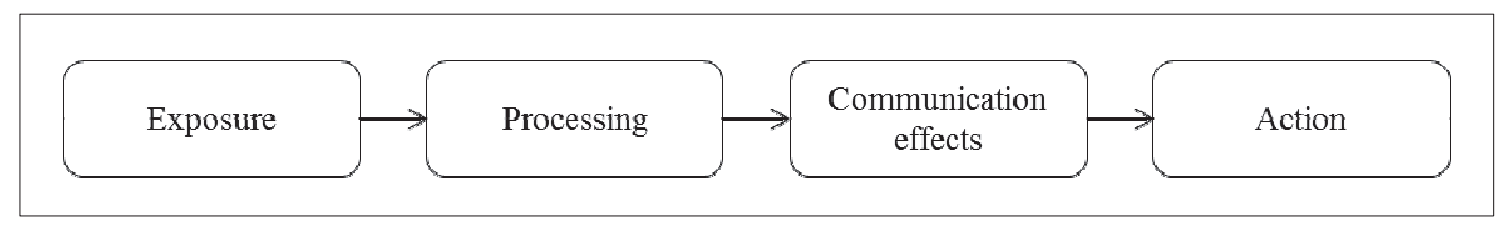

〈Figure 4〉 Waller's Response Model for Controversial Advertising (2006)

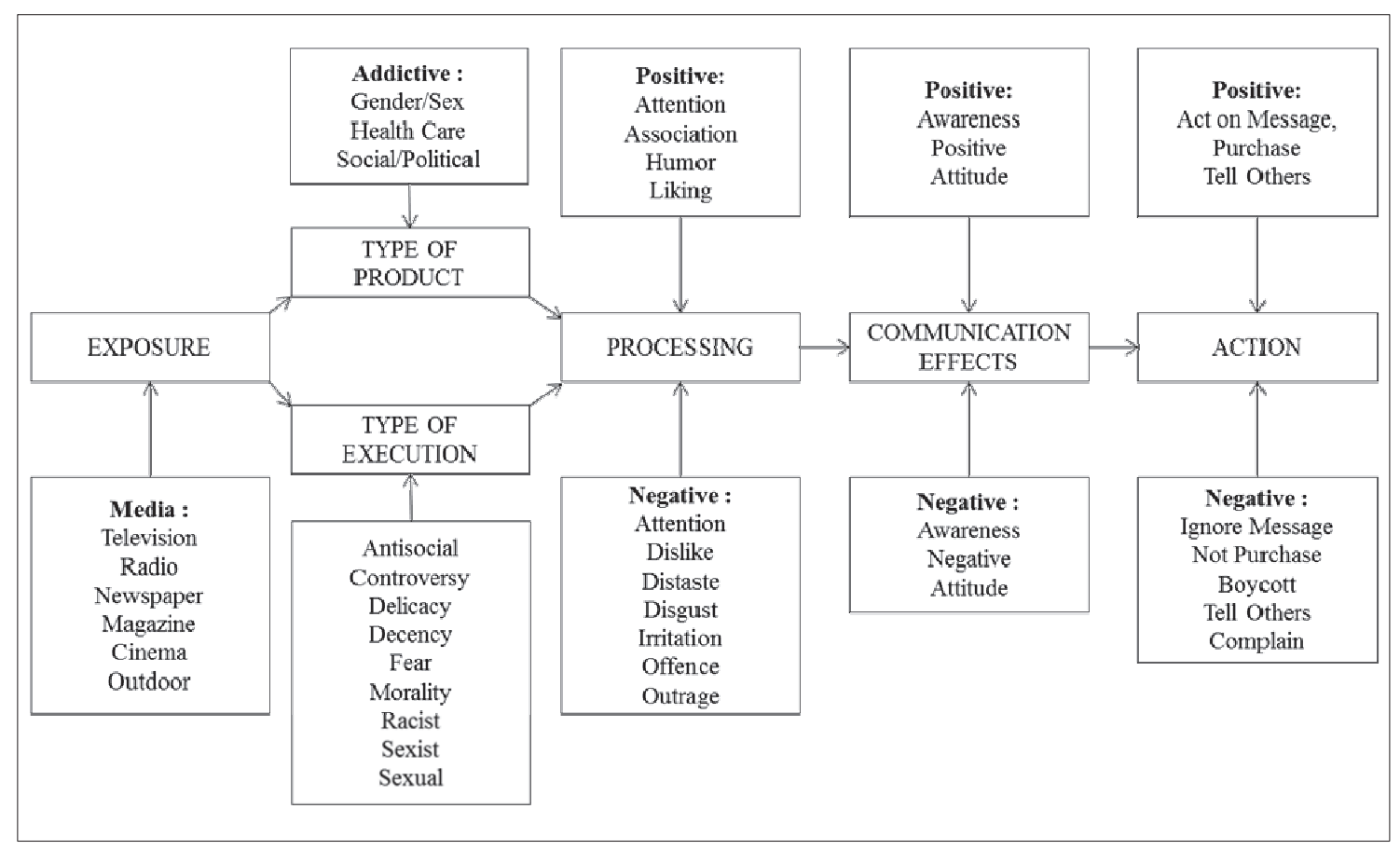

their exposure to advertising is not just a summed up representation of judgements generated in each stages of the models, but rather an outcome of values cumulated from the very first stage of "exposure" to the rest of the stages. Hence, in order to elicit positive behavior from consumers, advertisers should not focus on a single stage to bring out affirmative responses but engage in all stages that precedes the final stage of "action".

The previous research concerning controversial products and advertising had their focus on defining and categorization of its terminology. Based on such, other studies try to prove the relationship between consumer's cultural values and its impact on building perception toward controversial advertising; however, their scope is still very limited in showing the potential 
impact of socially controversial advertisings on consumer actions. Respectively, this study intends to adopt Waller's (2006) model to examine how consumers differ in their responses when exposed to advertisings of both controversial and genuine products by observing the change in their attitudes toward the endorsers and the product itself. The study also investigates the role of media to explore the extent to which the attitude varies with different media platform.

\section{Theoretical Framework}

In examining the effect of advertisements on consumers, the available works in the field have dispersed focus of interest. For instance, Keller (1987), Meenaghan (1995) and Rupani (2006) have the brand image as the center of attention in their works, while others like Yi (1993) and Rechmann and Kight (2002) incorporated consumers' previous knowledge of brands, and peer opinions in observing the effects of advertising.

This study aims to contribute to the current field of research by employing the "endorsement effect" in a reversed way to show the impact of controversial advertisings on consumers in evaluating the image of the endorsed persons, and applies the Source Credibility Model to evaluate the level of credibility of the endorser, as well as to observe the role of media credibility in moderating the impact of controversial advertising.

\subsection{Credibility of Endorser and Media on Consumer Evaluation}

As a means to communicate with consumers in a familiar way, large number of brands are employing renowned figures in their advertisements. In his study, McCarken (1989) refers to such person with public acknowledgement as an endorser, where their credibility is utilized to benefit a product or service. In fact, the attempts to discover the presence of "endorsement effect" for advertisers were witnessed in a number of previous studies. The works of Cameron (1994), Choi, Lee, and Kim (2005), and Fireworker and Friedman (1977) observed the impact of celebrities and sports stars on the images of brands and products.

While the "endorsement effect" usually refer to the endorser's impact on the brand, this study intends to reverse the concept and examine the impact of the advertisements on the endorsers. In other words, this study explores how advertising controversial products and services influence consumers' evaluations of the endorsers. In order to observe how the endorsers are evaluated by consumers the Source Credibility model by Goldsmith, Lafferty, and Newell (2000) and Ohanian (1991), and the Source Attractiveness Model by Till and Buiser (2000) are referred to. The "source credibility" associates with the 
degree of acceptability consumers display toward the endorsers. The level of tolerance, as suggested by Shimp (2010), is generally decided based on the perceived image (e.g. looking trustworthy, cheerful, or gloomy) of an endorser by the viewer, which can significantly affect the effectiveness of advertising. Similarly, the “source attractiveness" relates with the endorser's physical appeals, thus the perceived personality, intellectual capacity, and lifestyle of the figure by consumers.

It can be inferred from both models that the greater credibility and attractiveness of endorsers would generate beneficial outcome for evaluation of endorsers, as well as the product. In fact, Shimp (2010) proposes that there is larger chance for consumers to accept the endorser's attitudes, behaviors and preferences positively when their perceived attractiveness of the endorser is high. In similar sense, Tom, Clark, Elmer, Grech, Masetti Jr, and Sandhar (1992) also projects that the positive attitude towards endorsers is more likely to generate positive outcome for the endorsed product as well.

As it has been projected above, and again emphasized in the works of Choi and Rifon (2002), Moore and Rodgers (2005), and Perloff (1993), source credibility is an essential component for an advertisement to strengthen the power of its message. Along with the endorsers, Petty and Cacioppo (1996) refers to the type of media an advertisement is delivered through as another "source" of credibility that influences consumer attitudes. For an advertising message to appear efficacious, having the right medium of delivery, therefore media credibility, is crucial; otherwise it may be disregarded or even evaded by consumers no matter how persuasive the message is. Likewise, Chan, Leung, and Wong's (2006) research suggests that the low level of media credibility associates with greater uncertainty of consumers for the products advertised through that media. The discrepancy in the level of consumer's reliability on different types of media was observed by Moore and Rodgers (2005), where newspaper was ranked to have the highest credibility, followed by television, magazine, radio, and the Internet.

\subsection{Heider’s Balance Theory}

It is evident that source and media credibility can influence consumers' attitudes toward advertising to a significant degree. To explain why such changes occur, Heider's (1946) Balance Theory was used. This theory shows individual's tendency to develop a balanced relationship with the surrounding environments. Here, three different elements, the person him/ herself analyzing the environment $(\mathrm{P})$, another individual $(\mathrm{O})$ and an object (X) being compared to, are used to demonstrate how the relationship forms a balance. The relationship between the elements are represented as either positive $(+)$ or negative $(-)$, producing the total of 8 possible linkages (refer to Figure 5 and 6). 
〈Figure 5〉 Balanced States Among the Analyzing Person (P), A Person of Comparison (0) and an Object of Comparison (X)

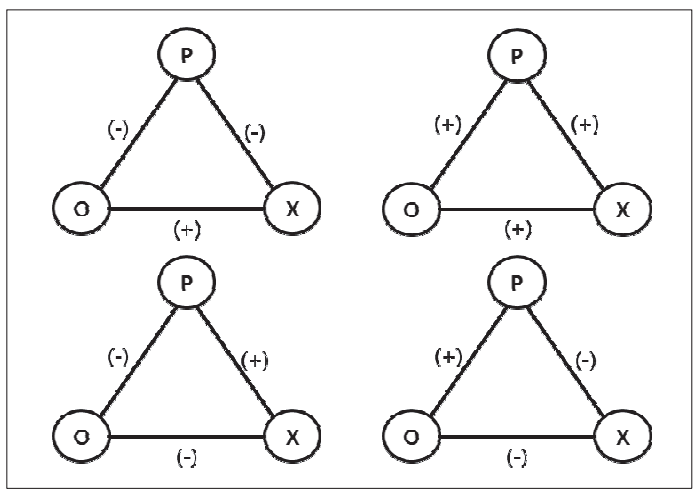

〈Figure 6> Imbalanced States Among the Analyzing Person ( $P$ ), Person of Comparison ( 0 ) and an Object of Comparison ( $X$ )

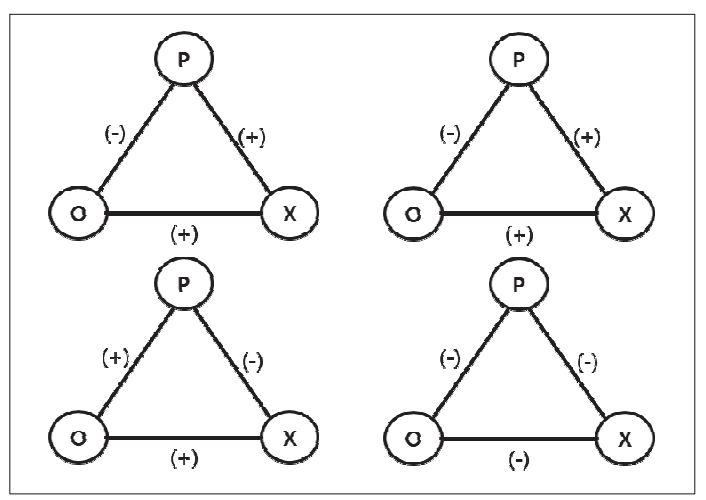

Through this the individual's cognitive consistency can be elucidated, which, as elaborated by Insko (2012), is individuals' psychological desire to maintain their values and beliefs balanced over time. Thus, an individual may feel distressed in a situation that causes an imbalance of the relationship, and as a result, his/her attitude toward the compared individuals and/or the objects will be modified to differ with the previous relationship. In this process of adjusting the relationship, Woodside and Chebat (2001) suggests that the individual's attitude toward the compared individuals and objects are altered according to the level of affection he/she has for each.

\subsection{Hypotheses}

To examine the impact of advertising of socially controversial products on its viewers, this study intends to observe the change in viewer's attitude toward the featured endorser; the advertisement's medium of delivery (TV Program); and the product itself. We assumed that advertising of socially controversial products affects those relative media attributes under the existing media-effect related literature. Hence the following hypotheses are drawn:

H1: Advertising of socially controversial product will negatively influence the viewer's attitude toward the endorser.

H2: Advertising of socially controversial product will negatively influence the viewer's attitude toward the medium of delivery.

H3: Advertising of socially controversial product will negatively influence the viewer's attitude toward the advertised product. 
This research also aims to investigate the moderating effect of media credibility and its presence over the relationships between the advertising, the endorsers, the delivered medium, and the product. The effect of recognized media credibility is well-known to affect the message credibility in audiences' minds. Thereby the relationship between the advertisement and media attributes in hypotheses 1-3 would be moderated by media credibility recognized by viewers and the following hypotheses are drawn:

H4: H1 will be moderated by the viewer's credibility of the media.

H5: H2 will be moderated by the viewer's credibility of the media.

〈Figure 7〉 Balanced States Among Consumer (P), Media (0), and Endorser/Medium of Delivery (TV Program)/Advertised Product (X)

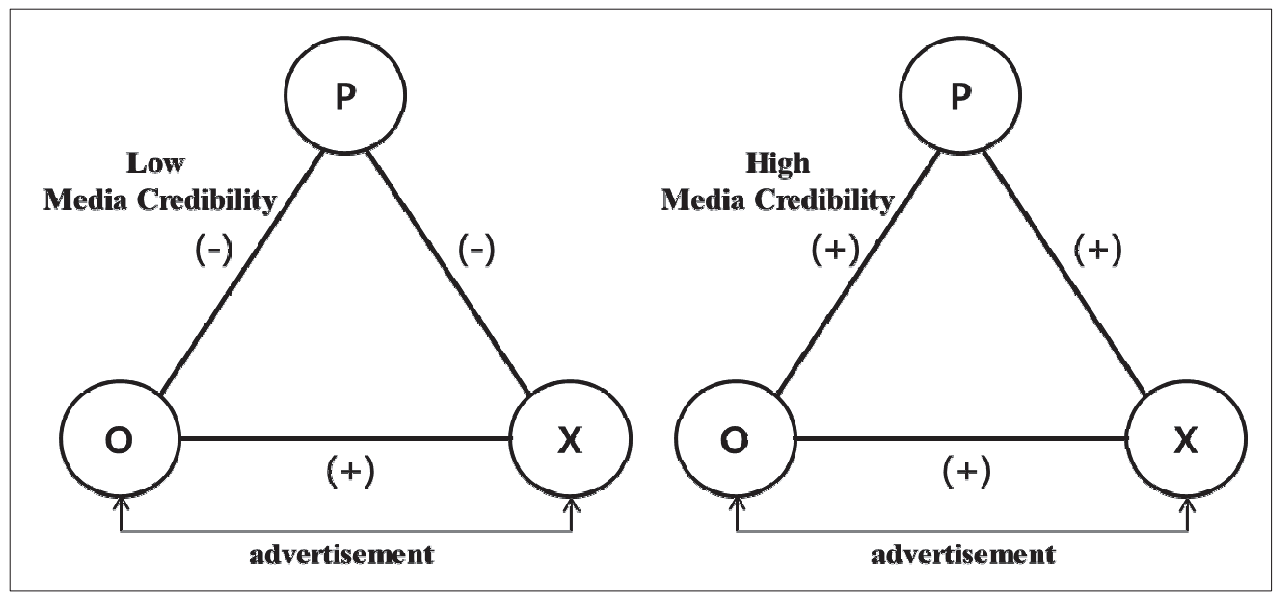

〈Figure 8> Research Model

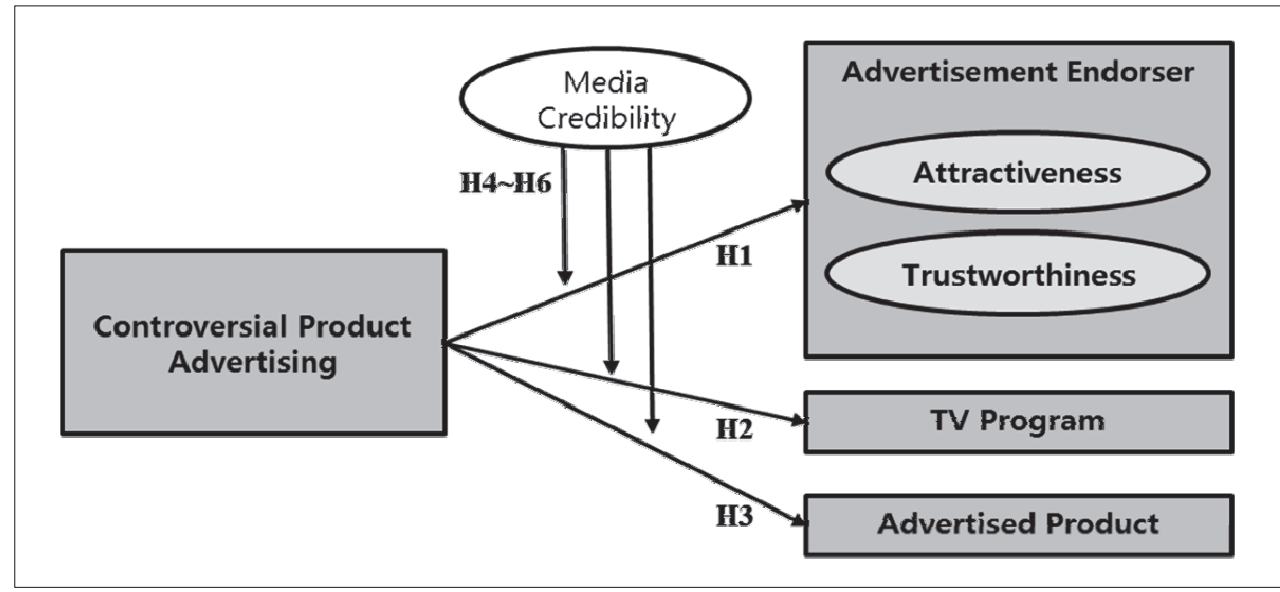


H6: H3 will be moderated by the viewer's credibility of the media.

Based on Heider's (1946) Balance Theory, this study assumes the viewer's attitude $(\mathrm{P})$ toward the endorsers; the medium of delivery (TV Program); and the product (X) to be negative when media credibility $(\mathrm{O})$ is low relative to when it is high (refer to Figure 7). Derived from this assumption, this work proposes the research model as constructed in Figure 8.

\section{Research Methodology}

In order to observe the viewers' attitude change concerning the endorsers; the medium of delivery; and the product when advertising socially controversial product to that of a genuine product, this research adopted product placement (PPL) in a television soap opera as a medium of delivery, featured actresses as the endorsers, and paprika as the product. To make the comparison possible, the paprika was labeled differently as organic grown to represent the genuine product, or genetically modified for the socially controversial product and was shown to separated groups.

\subsection{Data Collection}

The experiment was conducted using Qualtrics survey software, represented by the total of 174 subjects (104 females and 74 males) out of 192 respondents that have satisfied the requirements. Samples were collected through an online survey, where the participants were to participate in two surveys with a two-day interval in between the surveys. To make comparison of attitude change towards controversial product advertising possible, the participants completed one survey prior to watching a video stimulus which included a scene from a television soap opera, the "Queen of Housewives" (2009), and then proceeded to the second survey, where 87 respondents were given different information to the rest of remaining 87 participants.

The first survey $\left(T_{1}\right)$ intended to measure the respondents' attitude toward the endorser (the cast of "Queen of Housewives"), the program itself ("Queen of Housewives"), and the product (paprika), along with their credibility of the media (TV product placement). After completing the survey, all participants were shown the stimulus which displayed a paprika in the center of the scene from the "Queen of Housewives" as a subject of product placement (PPL). While the video clip shown to all participants was identical, using different subtitles, one half of the respondents were informed of the paprika as organic, while the other half as genetically modified product (see Figure 9). Upon watching the clip, the second survey $\left(\mathrm{T}_{2}\right)$ was conducted to measure the change in the participants' attitude toward the endorser; 
〈Figure 9〉 PPL Scene from Soap Opera for Advertising Genetically Modified Paprika (Left) and Organic Paprika (Right)

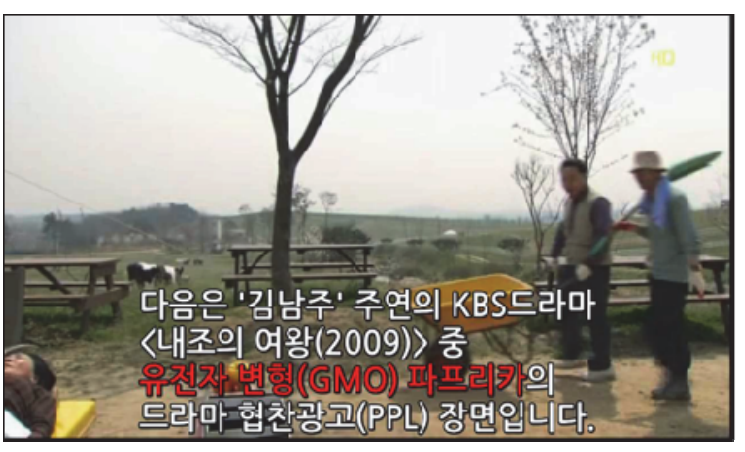

the program; and the product caused by being exposed to the stimulus.

\subsection{Measurement Development}

In both surveys, the questions were designed to measure the participants' perception toward the endorser; the medium of delivery; the product itself; and the media credibility. All questions were answered using a using a seven-point Likert scale ( $1=$ "strongly disagree" to 7 = "strongly agree").

For development of the questions observing the attitude toward the endorser, Ohanian's (1990) work was referred to. Three separate items measured whether the participants considered the endorser (cast of the "Queen of Housewives") trustworthy, experienced, and attractive as a celebrity.

The questions for observing the attitude toward the medium of delivery (TV program) were designed based on Neelamegham's (1999)

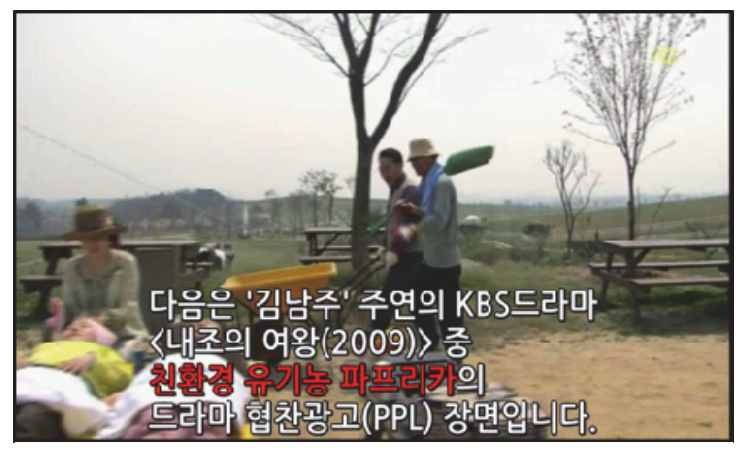

pre-choice expectation questionnaire. Five separate questions were answered after being informed of a brief plot of the TV program, which measured the participants' expectations on the program's performance; plot; featured casts; entertainment; and attractiveness.

For questions measuring the participants' attitude toward the product itself and its attributes (socially controversial or genuine), Pieniak's (2010) questionnaire on general attitudes of consumers toward organic vegetables was employed and modified to develop three individual questions for each attributes. The items asked the participants' preference of the product ("I really hate-love organic/genetically modified products"), feelings upon consumption ("When I eat organic/genetically modified products, I feel bad-good”), and opinion of the product ("I think negatively-positively of organic/genetically modified products").

To measure the participants' credibility on the medium of delivery (TV program), three 
individual questions were developed based on Lafferty's (1999) questionnaire. The questions asked about the degree to which the participant trust TV as a media, dependency as a source of information, and perceived transparency.

\section{Results}

The change in the participants' attitude toward the endorser; the program; and the product were observed by calculating the differences between the two surveys, $T_{1}$ and $\mathrm{T}_{2}$ (Attitude change $=\mathrm{T}_{2}-\mathrm{T}_{1}$ ). The t-test was used for $\mathrm{H} 1$ to $\mathrm{H} 3$, to determine the impact of the advertisement on the participants' attitude toward the endorser $\left(A_{e}\right)$; the program $\left(A_{s}\right)$; and the product $\left(A_{p}\right)$.

The respondents were divided into two groups: one was informed of the product as a genetically modified paprika which represented the socially controversial product, whereas the other group was informed of the paprika as organic to represent a genuine product. Using the two different conditions, an independent t-test was conducted (see Table 1). The results showed that $\mathrm{H} 1$ is accepted $(p=.020$, $p<.05)$ with the value of the participants' perception toward the endorser representing a greater decline in the case of genetically modified (GM) paprika relative to that of the organic paprika $\left(M_{G M}=-.2705\right.$ with $M_{O R G A N I C}=$ -.0057).

On the other hand, the participants' attitude toward the TV program and the product appeared insignificant, thereby rejecting $\mathrm{H} 2$ $(p=.988)$ and $\mathrm{H} 3(p=.263)$ respectively. However, the overall result verified that advertising of controversial products through PPL on television soap operas have negative impacts on consumers' attitudes toward the endorsers.

This study also confirmed the moderating effect of media credibility in the relationship between the participants' attitude toward the endorser; the program; and the product. The differences between the two groups of samples

$\langle$ Table 1〉 Results of independent Sample t-test

\begin{tabular}{|c|c|c|c|c|c|c|}
\hline Attitude changes & Group & Mean & $\begin{array}{l}\text { Standard } \\
\text { deviation }\end{array}$ & $\mathrm{df}$ & $\mathrm{t}$-value & $p$-value \\
\hline \multirow{2}{*}{ Endorser $\left(A_{e}\right)$} & GM & -.2705 & .56460 & \multirow{2}{*}{165.796} & \multirow{2}{*}{-2.353} & \multirow{2}{*}{$.020^{* *}$} \\
\hline & Organic & -.0057 & .88457 & & & \\
\hline \multirow{2}{*}{ TV Soap opera $\left(A_{s}\right)$} & GM & .3264 & .88966 & \multirow{2}{*}{172} & \multirow{2}{*}{.015} & \multirow{2}{*}{.988} \\
\hline & Organic & .3241 & 1.08220 & & & \\
\hline \multirow{2}{*}{ Product attributes $\left(A_{p}\right)$} & GM & .2206 & .91068 & \multirow{2}{*}{172} & \multirow{2}{*}{1.122} & \multirow{2}{*}{.263} \\
\hline & Organic & .0403 & 1.18961 & & & \\
\hline
\end{tabular}


were statistically significant at one percent, where the impact of advertising of controversial products on the viewers' attitude toward the endorser was moderated by media credibility $\left(p=.035^{* *}, p<.05\right)$.

The result suggests that the change in viewer's attitude toward the endorser may be greater when television is used as a medium of delivery for advertising of socially controversial products, and the degree of change is expected to be greater for the viewers with negative perception toward the advertised product. However, if the viewers display higher level of trust for television, the change may be less evident.

\section{Discussions and Implications}

Through the empirical findings, this study contributes to the expansion of the current literatures on socially controversial products and advertising. While there are a number of researches like that of Cameron (1994), Choi et al. (2005), and Fireworker and Friedman (1977), which have successfully illustrated the impact of celebrity endorsement on the image of the products and brands; this extends from the previous works to observe the endorsement effect in the reverse. With such focus, this study intended to show the power of products' attributes in affecting the image of their endorser. And the results also confirmed that advertising negatively labelled products - e.g. socially controversial goods - have negative impact upon the endorser's image, verifying the reversed effect of endorsement.

Another focus of this study was on media credibility, to examine the significance of consumer's trust in different types of media. There are previous studies that have explored the relationship between the media credibility and advertisements (Petty and Cacioppo 1996, Chan, Leung and Wong 2006, Moore and Rodgers 2005). However, in this work, media credibility was incorporated as a moderator in examining the effect of advertising of socially controversial products on consumers' attitude of the endorsers by using television as a medium of delivery.

The results indicated that advertising of controversial products through media with low credibility tend to generate negative attitude among consumers toward the endorsers than when the credibility is higher. Thereby, the moderating effect of media credibility in the relationship between the advertising; consumers; and endorsers was verified.

It was also concluded that the consumers tend to develop negative attitude toward the endorser when advertising socially controversial products on television; whereas their attitude toward the product itself did not change. Based on such results, this study suggests possible grounds of implication for its practical application 
among marketers.

The outcome of this research recommends marketers to reconsider the use of celebrity endorsement when advertising socially controversial products if their aim is to generate positive sentiments among consumers, as well as to maximize the benefit of the advertisers. Perhaps, it may be more advantageous for the products to be advertised through product placement, also known as "on-set placement" or "creative placement" (Babin and Carder 1996, Solomon 1996, Vollmers and Mizerski 1994). When using such strategy, it is also considered ideal to minimize the involvement of endorsers in promoting the products.

\section{Limitations}

The objective of this research was to highlight the impact of advertising of socially controversial products on Korean consumers' evaluation of the endorsers. While the findings present some degree of achievements for both practical and theoretical implications; there are also several grounds of considerations for future researches.

The previous works have noted that the consumers tend to act in a way that corresponds with their perception (Heider 1946, Insko 2012, Rossiter and Percy 1987, Waller 2006, Woodside and Chebat 2001). Based on such notion, it can be assumed that the consumers' negative attitude toward a certain product may be reflected in their purchase patterns and when spreading a word-of mouth. However, with the primary purpose of this study on investigating the impact of advertising of socially controversial products on consumers' evaluation of the endorsers; the medium of delivery; and the product, the results failed to provide a valid evidence to explain this tendency.

Hence, it may be a worthwhile avenue for future researches to build upon this work to observe whether consumers' perception toward a socially controversial product actually extends to affect their behaviors toward the product and/or the endorser in the reality, denoted by their tendency to refrain from purchasing the product or spreading a negative word of mouth, and to provide explanations for such tendency. This seems to be a meaningful approach, considering the prevalence of socially controversial products in the market and the greater level of risk that may be associated with the image of the endorsers in reality.

Another area of concern is the type of product that was used to conduct the experiment. This study incorporated an agricultural product to represent both genuine and socially controversial products by allocating two different attributes, organic and genetically modified, to a paprika. For further researches, it is recommended to extend the investigation using alternative type of socially controversial products. The suggestions 
include those products beyond agricultural goods, like gender related merchandises, as well as the campaigns for human rights and political interests, to broaden the scope.

The media credibility also played a significant role in this research, as a moderator on the impact of socially controversial products on the viewers' evaluation of different elements. In similar sense, it seems plausible for future works to expand its realm by using alternative factors to examine their potential influence upon the viewers' attitude toward the endorsers and the products.

〈Received May 13. 2017〉

〈Accepted August 9. 2017〉

\section{References}

Babin, Laurie A, and Sheri Thompson Carder. 1996. "Viewers' recognition of brands placed within a film." International journal of advertising no. 15(2), 140-151.

Barnes Jr, James H, and Michael J Dotson. 1990. "An exploratory investigation into the nature of offensive television advertising." Journal of Advertising no. 19(3), 61-69.

Cameron, Glen T. 1994. “Does publicity outperform advertising? An experimental test of the third-party endorsement." Journal of Public Relations Research no. 6(3), 185-207.

Chan, Ricky YK, TKP Leung, and YH Wong.
2006. "The effectiveness of environmental claims for services advertising." Journal of Services Marketing no. 20(4), 233-250.

Choi, Sejung Marina, and Nora J Rifon. 2002. "Antecedents and consequences of web advertising credibility: A study of consumer response to banner ads." Journal of Interactive Advertising no. 3(1), 12-24.

Choi, Sejung Marina, Wei-Na Lee, and HeeJung Kim. 2005. "Lessons from the rich and famous: A cross-cultural comparison of celebrity endorsement in advertising." Journal of Advertising no. 34(2), 85-98.

Erdogan, B Zafer. 1999. "Celebrity endorsement: A literature review." Journal of marketing management no. 15(4), 291-314.

Fahy, John, Denise Smart, William Pride, and OC Ferrell. 1995. "Advertising sensitive products." International Journal of Advertising no. 14(3), 231-243.

Fam, Kim Shyan, and David S Waller. 2003. "Advertising controversial products in the Asia Pacific: what makes them offensive?" Journal of Business Ethics no. 48(3), 237250.

Fam, Kim Shyan, David S Waller, and B Zafer Erdogan. 2004. "The influence of religion on attitudes towards the advertising of controversial products." European Journal of Marketing no. 38(5-6), 537-555.

Fam, Kim Shyan, David S Waller, Fon Sim Ong, and Zhilin Yang. 2008. "Controversial product advertising in China: perceptions 
of three generational cohorts." Journal of Consumer Behaviour no. 7(6), 461-469.

Fireworker, Robert B, and Hershey H Friedman. 1977. "The effects of endorsements on product evaluation." Decision Sciences no. 8(3), 576-583.

Fritz, Heider. 1958. "The psychology of interpersonal relations." The Journal of Marketing no. 56, 322.

Goldsmith, Ronald E, Barbara A Lafferty, and Stephen J Newell. 2000. "The impact of corporate credibility and celebrity credibility on consumer reaction to advertisements and brands." Journal of Advertising no. 29 (3), 43-54.

Insko, Chester A. 2012. "Balance-logic theory." Handbook of theories of social psychology no. 1, 178-200.

Keller, Kevin Lane. 1987. "Memory factors in advertising: The effect of advertising retrieval cues on brand evaluations." Journal of Consumer Research, 316-333.

Lafferty, Barbara A, and Ronald E Goldsmith. 1999. "Corporate credibility's role in consumers' attitudes and purchase intentions when a high versus a low credibility endorser is used in the ad." Journal of business research no. 44(2), 109-116.

Lavidge, Robert J, and Gary A Steiner. 1961. "A model for predictive measurements of advertising effectiveness." The Journal of Marketing, 59-62.

MacKenzie, Scott B, Richard J Lutz, and
George E Belch. 1986. "The role of attitude toward the ad as a mediator of advertising effectiveness: A test of competing explanations." Journal of marketing research, 130-143.

McCracken, Grant. 1989. "Who is the celebrity endorser? Cultural foundations of the endorsement process." Journal of consumer research, 310-321.

Meenaghan, Tony. 1995. "The role of advertising in brand image development." Journal of Product \& Brand Management no. 4(4), 23-34.

Miciak, Alan R, and William L Shanklin. 1994. "Choosing celebrity endorsers." Marketing Management no. 3(3), 50.

Moore, Jensen J, and Shelly L Rodgers. 2005. An examination of advertising credibility and skepticism in five different media using the persuasion knowledge model. Paper read at American Academy of Advertising. Conference. Proceedings.

Neelamegham, Ramya, and Dipak Jain. 1999. "Consumer choice process for experience goods: An econometric model and analysis." Journal of Marketing Research, 373-386.

Ohanian, Roobina. 1990. "Construction and validation of a scale to measure celebrity endorsers' perceived expertise, trustworthiness, and attractiveness." Journal of advertising, 39-52.

Ohanian, Roobina. 1991. "The impact of celebrity spokespersons' perceived image on consumers' 
intention to purchase." Journal of advertising Research.

Pechmann, Cornelia, and Susan J Knight. 2002. "An experimental investigation of the joint effects of advertising and peers on adolescents' beliefs and intentions about cigarette consumption." Journal of Consumer Research no. 29(1), 5-19.

Percy, Larry, and John R Rossiter. 1997. Advertising communication and promotion management. New York: McGraw-Hill.

Perloff, RM. 1993. The Dynamics of Persuasion. General Communication Theory and Methodology. Lawrence Erlbaum Associates, Inc., Pub., Hillsdale, New Jersey. 411pp.

Petty, Richard E, and John T Cacioppo. 1996. Attitudes and persuasion: Classic and contemporary approaches: Westview Press.

Phau, Ian, Gerard Prendergast, and Leung Hing Chuen. 2001. "Profiling brand-piracy-prone consumers: An exploratory study in Hong Kong's clothing industry." Journal of Fashion Marketing and Management: An International Journal no. 5(1), 45-55.

Pieniak, Zuzanna, Joris Aertsens, and Wim Verbeke. 2010. "Subjective and objective knowledge as determinants of organic vegetables consumption." Food quality and preference no. 21(6), 581-588.

Rehman, Sharaf N, and John R Brooks Jr. 1987. "Attitudes toward television advertisements for controversial products." Journal of health care marketing no. 7(3), 78.
Rossiter, John R, and Larry Percy. 1987. Advertising and promotion management: McGraw-Hill Book Company.

Rupani, Puja. 2006. The Effect of Advertising on Brand Image: A Consumers Perspective, University of Nottingham.

Schuster, Camille P, and Christine Pacelli Powell. 1987. "Comparison of cigarette and alcohol advertising controversies." Journal of Advertising no. 16(2), 26-33.

Shimp, Terence A. 2010. "Integrated Marketing Communication in Adver-tising and Promotion 8e." International Edition. Printed in China.

Solomon, MR. 1996. Consumer behavior. Englewood Cliffs. NJ: Prentice-Hall.

Strong, Edward Kellogg. 1925. The psychology of selling and advertising: McGraw-Hill book Company, Incorporated.

Till, Brian D, and Michael Busler. 2000. "The match-up hypothesis: Physical attractiveness, expertise, and the role of fit on brand attitude, purchase intent and brand beliefs." Journal of advertising no. 29(3), 1-13.

Tom, Gail, Rebecca Clark, Laura Elmer, Edward Grech, Joseph Masetti Jr, and Harmona Sandhar. 1992. "The use of created versus celebrity spokespersons in advertisements." Journal of Consumer Marketing no. 9(4), 45-51.

Vollmers, Stacy, and Richard Mizerski. 1994. A review and investigation into the effectiveness of product placements in 
films. Paper read at Proceedings of the 1994 Conference of the American Academy of Advertising.

Waller, David S. 1999. "Attitudes towards offensive advertising: an Australian study." Journal of consumer marketing no. 16(3), 288-295.

Waller, David S. 2004. "What factors make controversial advertising offensive?: a preliminary study.”.

Waller, David S. 2006. “A proposed response model for controversial advertising." Journal of promotion management no. 11(2-3), 3-15.

Waller, David S, Kim-Shyan Fam, and B Zafer Erdogan. 2005. “Advertising of controversial products: a cross-cultural study.” Journal of Consumer Marketing no. 22(1), 6-13. Wilson, Aubrey, and Christopher West. 1981. "The marketing of unmentionables." Harvard Business Review no. 59(1), 91-\&.

Wilson, Aubrey, and Christopher West. 1995. "Commentary: permissive marketing-the effects of the AIDS crisis on marketing practices and messages." Journal of Product \& Brand Management no. 4(5), 34-48.

Woodside, Arch G, and Jean Charles Chebat. 2001. “Updating Heider's balance theory in consumer behavior: A Jewish couple buys a German car and additional buying - consuming transformation stories." Psychology \& Marketing no. 18(5), 475495. 